Archived version from NCDOCKS Institutional Repository http://libres.uncg.edu/ir/asu/

\title{
Appalachïan
}

B O O NE, NORTH CAROLINA

\section{Loss Aversion And A Kinked Demand Curve: Evidence From Contingent Behaviour Analysis Of Seafood Consumers}

\author{
By: Ashton Morgan
}

\begin{abstract}
Several laboratory experiments and market-based research in the fields of psychology, economics and marketing have provided increasing evidence of individuals exhibiting loss aversion tendencies, with decision-making based on a pre-existing reference point. This creates an S-shaped value function and associated kink in the demand curve. This research provides contingent behaviour analysis of 1790 seafood consumers across the Mid-Atlantic region. A survey is specifically designed to elicit respondents' change in consumption from their reference point when faced with price variations in the seafood market. Results from a Tobit model with random effects provide empirical support of consumers behaving in a manner consistent with loss aversion theory, revealing a kinked demand curve for seafood meals at the respondents' reference point.
\end{abstract}

Morgan, O. A. (2008) "Loss Aversion And A Kinked Demand Curve: Evidence From Contingent Behavior Analysis Of Seafood Consumers." Applied Economics Letters, 15(8): 625-628 (ISSN: 1350-4851). [DOI: 10.1080/13504850600721940] Version Of Record Available At www.tandfonline.com 


\section{INTRODUCTION}

Traditional economic theory contends that individuals should be thought of as rational economic agents, exhibiting consistent preferences that are independent of any current endowments and maximizing utility subject to a budget constraint. However, there is a strong body of empirical evidence testing the validity of traditional assertions, and these critics of traditional theory (behaviouralists) question individuals' cognitive capacity to act as rational economic agents, contending instead that individuals simplify complex decisions that they face.

Laboratory experiments (Thaler, 1980; Knetsch and Sinden, 1984, 1987; Knetsch, 1989; Kahneman et al., 1990; Tversky and Kahneman, 1991; Bateman et al., 1997) in the fields of psychology and economics provide evidence of individuals using a reference point to evaluate changes, and also reveal a disparity in individual behaviour based on whether the change is perceived as a loss or a gain. Specifically, experiments reveal that individuals tend to be more adverse to losses than they are to equal sized gains. This implies that the loss of utility associated with giving something up exceeds the utility gain associated with receiving something - individuals fear loss more than they crave gains.

Kahneman et al. (1991) discuss how loss aversion causes the slope of the value function to change at the origin, creating an S-shaped function. However, the asymmetry in an individual's valuation of a gain or a loss from the origin (reference point) also has implications for the associated demand function. If respondents exhibit behaviour in accordance with loss aversion, this should result in a demand curve that is kinked at a reference point.

While some research has looked to the market place to examine whether such consumer behaviour exists, (for example, see Bidwell et al., 1995 (telecommunications); Genesove and Mayer, 2001 (housing market); Ryan and Ubach, 2003 (heath care)), this research uses contingent behaviour analysis to directly observe changes in consumption patterns of seafood consumers when faced with price changes in the seafood market, in order to test 
whether consumers act in a manner consistent with loss aversion.

Point A represents the respondent's reference point, which in this analysis refers to their stated current level of seafood consumption. The number of seafood meals demanded at this point is shown as $x_{0}$. If respondents are behaving in a manner consistent with loss aversion, one should expect the demand curve to be kinked at this point. The reason being is that one can consider a decline in seafood meals demanded from the reference point $\left(x_{0}\right.$ to $\left.x_{1}\right)$, due to a price increase, as a loss to the consumer, and an increase in seafood meals demanded $\left(x_{0}\right.$ to $\left.x_{2}\right)$, due to a price decrease, as a gain. If consumers are more adverse to losses than to gains, the price increase necessary to induce the respondent to consume one less meal (loss) is greater than the price decrease necessary for the respondent to consume one more seafood meal (gain). That is, the change in price, $p_{0}$ to $p_{1}$ will exceed $p_{0}$ to $p_{2}$. The slope of the demand curve will therefore be kinked at the current level of seafood consumption, or the individual's reference point, with the steeper portion of the demand curve in the domain of a loss, or a price increase.

\section{DATA}

The research estimates a demand function for seafood meals through a contingent behaviour analysis of 1790 respondents (61\% response rate) throughout the Mid-Atlantic region. By survey design, contingent behaviour questions establish each respondent's reference point and their behaviour when asked to consider both price increases and decreases in seafood prices. Respondents were also asked various socioeconomic and seafood preference questions.[1] 


\section{METHOD AND MODEL OF SEAFOOD DEMAND}

The analysis is performed in the context of a demand model for seafood consumption. That model takes the form

$$
x=\beta_{p} p+\beta_{y} y+\beta_{s} s+\beta_{d} d+e
$$

where $x$ is the number of seafood meals consumed monthly, $p$ is the price of a seafood meal, $y$ is income, $s$ is a vector of variables believed to influence perceptions about risks and hence shift the seafood demand curve, and $d$ is a vector of socioeconomic variables.

In establishing a reference point for monthly seafood meals consumed, individuals report their current quantity demanded $x_{0}$ at the current price $p_{0}$. In terms of our demand model, we have

$$
x_{0}=\beta_{p} p_{0}+\beta_{y} y_{0}+\beta_{s} s_{0}+\beta_{d} d_{0}+e_{0}
$$

By survey design, respondents are asked how much their quantity of seafood meals demanded would change with a hypothetical change in price. Let $\Delta x$ be the reported change in the quantity demanded and $\Delta p$ the size of the hypothetical price change. This Gives

(3)

$$
x_{1}=\beta_{p}\left(p_{0}+\Delta p\right)+\beta_{y} y_{1}+\beta_{s} s_{1}+\beta_{d} d_{1}+e_{1}
$$

as the quantity demanded at the new

hypothetical price $\mathrm{p}_{0}+\Delta \mathrm{p}$. Subtracting Equation 2 from Equation 3 gives the demand difference equation

$$
\Delta x=\beta_{p} \Delta p+\left(e_{1}-e_{0}\right)
$$


where $\Delta x=x_{1}-x_{0}$ is the change in the quantity consumed in response to the hypothetical price increase. By survey design, the term

$\beta_{\mathrm{y}}\left(\mathrm{y}_{1}-\mathrm{y}_{0}\right)+\beta_{\mathrm{s}}\left(\mathrm{s}_{1}-\mathrm{s}_{0}\right)+\beta_{\mathrm{d}}\left(\mathrm{d}_{1}-\mathrm{d}_{0}\right)$ drops out of the demand difference because $\mathrm{y}_{1}=\mathrm{y}_{0}, \mathrm{~s}_{1}=\mathrm{s}_{0}$, $d_{1}=d_{0}$. The term $\left(e_{1}-e_{0}\right)$ is the difference in error terms, which I assume is nonzero.

We estimate $\beta_{p}$ using Equation 4. Variation in price comes from the survey design as individuals receive different price changes in the contingent behaviour questions. For a price increase, $\Delta p$ takes on a value of either $\$ 1, \$ 3, \$ 5$ or $\$ 7$. For a price decrease, it takes on a value of $\$-1, \$-2, \$-3$ or $\$-4$. I estimate separate equations for price-up and price-down in the analysis. These are

(5)

$$
\begin{aligned}
& \Delta x_{Q 1}=\beta_{p u} \Delta p_{u p}+\varepsilon_{Q 1} \quad n_{Q 1}=1680 \\
& \Delta x_{Q 2}=\beta_{p d} \Delta p_{\text {down }}+\varepsilon_{Q 2} \quad n_{Q 2}=1700
\end{aligned}
$$

where $\mathrm{n}_{\mathrm{Qi}}$ is the number of observations responding to question $i$ and $E_{\mathrm{Qi}}$ is an error term difference. Everyone in the sample is asked both questions, so the Equations in (5) are over the same people. Sample sizes vary slightly due to nonresponse in the survey instrument. The remaining component of the survey is designed to estimate shifts in the seafood demand function in response to local fish kills and different information treatments, providing three additional demand equations for the model.[2] The five equations are stacked to constrain the parameters across equations to be constant and to estimate the model with random effects.

Table 1. Regression results

\begin{tabular}{llcc}
\hline Variable & Description & Coefficient & $t$-statistic \\
\hline$\Delta p_{\text {up }}$ & Amount of price increase & -0.218 & -13.7 \\
$\Delta p_{\text {down }}$ & Amount of price decrease & -0.346 & -14.3 \\
major-kill & Dummy variable for a major fish kill & -1.19 & -8.0 \\
minor-kill & Dummy variable for a minor fish kill & -1.27 & -9.2 \\
brochure & Dummy variable for a brochure included in the survey & -0.089 & -0.7 \\
brochure \& insert & Dummy variable for a brochure and insert included in the survey & 0.076 & 0.6 \\
inspection & Dummy variable for an inspection program in place & 1.06 & 8.0 \\
price for inspection & Price increase due to an inspection program & -0.183 & -6.8 \\
\hline
\end{tabular}




\section{RESULTS}

The regression results appear in Table 1.[3] Upon inspection of the results, the coefficients on a price increase, $\Delta p_{\text {up }}$ and a price decrease, $\Delta p_{\text {down }}$ are significant but clearly differ in magnitude. The coefficient on $\Delta \mathrm{p}_{\text {down }},(-0.346)$, exceeds the coefficient on $\Delta \mathrm{p}_{\text {up }},(-0.218)$. Quantity demanded is more responsive to a price decrease than a price increase. This creates a kink in the demand function at the respondent's reference point (Point A in Fig. 1). This result reveals that respondents are behaving in a manner consistent with loss aversion as the price increase necessary to induce a loss is greater than the price decrease required to induce an equivalent gain. Consumers fear loss more than they crave a gains.

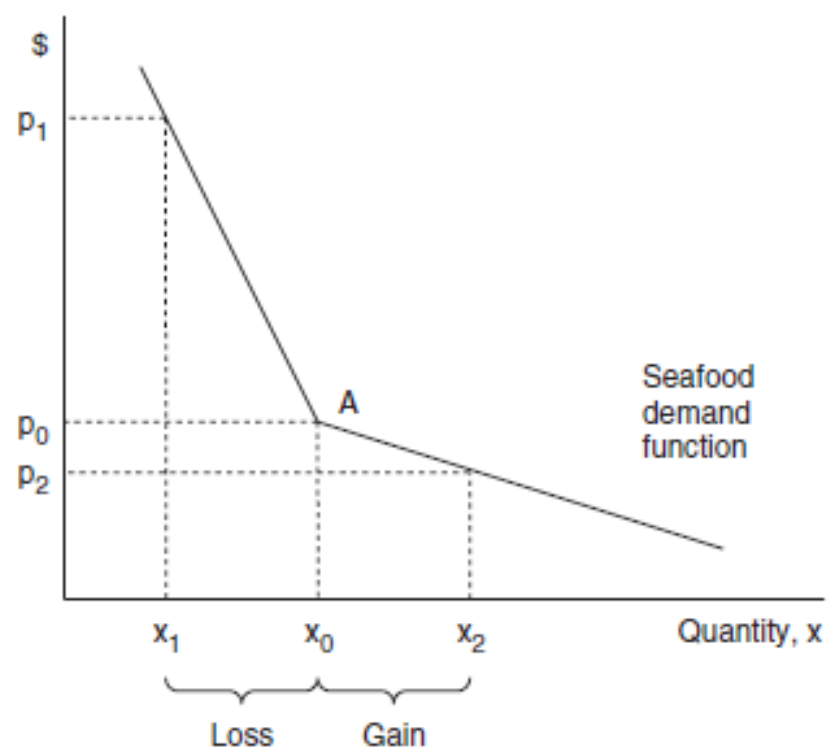

Fig. 1. Kinked demand curve

\section{CONCLUSION}

Over the last two decades, many laboratory experiments have supported the behaviouralist notion that individuals view choices differently depending on whether they perceive an action to be a gain or a loss from a reference point. These experiments have shown that consumers are generally more adverse to 
losses than they would be to equal sized gains. This article presents evidence of consumers behaving in a manner consistent with loss aversion. A contingent behaviour analysis of 1790 seafood consumers reveals that respondents require a disproportionately large price increase in order to reduce their seafood consumption compared to the price decrease required to induce an equal sized increase in seafood consumption. This creates a demand function that is kinked at the individual's reference point.

\section{NOTES}

1 These questions relate to other research not relevant to this discussion. For more information, please contact the author.

2 The three additional equations provide a total of five equations to be estimated in the model.

3 The coefficients on major-kill, minor-kill, brochure, brochure \& insert, inspection and price for inspection are demand shifters relating to information effects not discussed herein. For an explanation of these coefficients, contact the author.

\section{REFERENCES}

Bateman, I., Munro, A., Rhodes, B., Starmer, C. and Sugden, R. (1997) A test of the theory of reference dependent preferences, Quarterly Journal of Economics, 112, 479-505.

Bidwell Jr, M. O., Wang, B. X. and Zona, J. D. (1995) An analysis of asymmetric demand response to price changes: the case of local telephone calls, Journal of Regulatory Economics, 8, 285-98.

Genesove, D. and Mayer, C. (2001) Loss aversion and seller behavior: evidence from the housing market, Quarterly

Journal of Economics, 116, 1233-60.

Kaheman, D., Knetsch, J. L. and Thaler, R. H. (1990) Experimental tests of the endowment effect and the coase theorem, The Journal of Political Economy, 98, 1325-48. 
Kaheman, D., Knetsch, J. L. and Thaler, R. H. (1991) Anomalie: the endowment effect, loss aversion, and status quo bias, The Journal of Economic Perspectives, 5, 193-206.

Knetsch, J. L. (1989) The endowment effect and evidence of nonreversible indifference curves, American Economic Review, 79, 1277-84.

Knetsch, J. L. and Sinden, J. A. (1984) Willingness to pay and compensation demanded:

experimental evidence of an unexpected disparity in measures of value, Quarterly Journal of Economics, 99, 507-21.

Knetsch, J. L. and Sinden, J. A. (1987) The persistence of evaluation disparities, Quarterly Journal of Economics, 102, 691-5.

Ryan, M. and Ubach, C. (2003) Testing for an experience endowment effect in health care, Applied Economics Letters, 10, 407-10.

Thaler, R. (1980) Toward a positive theory of consumer choice, Journal of Economic Behavior and Organization, 1, 39-60.

Tversky, A. and Kahneman, D. (1991) Loss aversion in riskless choice: a reference dependent model, Quarterly Journal of Economics, 106, 1039-61. 